\author{
José María LAMIRÁN-PALOMARES
}

Universitat Politècnica València. Spain. jolapa@doctor.upv.es. https://orcid.org/0000-0001-5203-2643

\title{
Dr. Amparo BAVIERA-PUIG
}

Universitat Politècnica València. Spain. ambapui@upv.es. https://orcid.org/0000-0002-2258-1 155

\section{Dr. Tomás BAVIERA}

Universitat Politècnica València. Spain. tobapui@upv.es. http://orcid.org/0000-0002-2331-6628

\section{Who leads the conversation? Influential Twitter users during a niche sporting event ¿Quién lidera la conversación? Los usuarios influyentes de Twitter durante un evento deportivo de nicho}

Dates | Received: 18/07/2021 - Reviewed: 07/11/2021 - In press: 16/1 1/2021 - Published: 01/01/2022

\begin{abstract}
Fans of niche sports generally find minimal content in mainstream media due to their limited audience. Instead, social media offers them the opportunity to follow these specific sports. The dynamics behind digital media are based on individual participation, hence some prominent users lead the social conversation thanks to their capacity to influence. However, the complexity of the concept of influence and the existence of multiple parameters for its measurement make it difficult to identify these key users. Our research proposes a measure of the influence on Twitter based on variables derived from the platform (number of tweets, number of retweets, and number of followers) and from the Social Network Analysis (outdegree, indegree, and PageRank). The Analytic Hierarchy Process was used to assign a weight to each variable. This measure of influence was applied to the conversation generated on Twitter around a niche sporting event: the $2018 \mathrm{UCl}$ Track Cycling World Championships. From a 19 701-tweet corpus, we identified the 25 most influential users. The results indicate that the organisers and the participating cyclists played a relevant role in the Twitter conversation. In addition, the geographic distribution of these influential users reflects the cultural dependence of niche sports.
\end{abstract}

\section{Keywords}

AHP; cycling; niche sports; influential users; sporting events; Twitter

\section{Resumen}

Los seguidores de los deportes de nicho suelen encontrar escaso contenido en los medios de comunicación debido a su limitada audiencia. En cambio, los medios sociales permiten seguir estos deportes específicos. El dinamismo de estos medios se basa en la participación individual, de tal forma que usuarios prominentes conducen la conversación social gracias a su capacidad de influencia. Sin embargo, la complejidad del concepto de influencia dificulta identificar a estos usuarios clave. Nuestra investigación propone una medida de la influencia en Twitter basada en variables obtenidas de la plataforma (número de tweets, número de retweets y número de seguidores) y otras calculadas a partir del Análisis de Redes Sociales (outdegree, indegree y PageRank). Para componer este índice se utilizó el Proceso de Jerarquía Analítica. Esta medida se aplicó a la conversación generada en Twitter en torno a los Mundiales de Ciclismo en Pista 2018. A partir de un corpus de 19.701 tweets, identificamos a los 25 usuarios más influyentes del evento. Los resultados indican que los organizadores y ciclistas participantes jugaron un papel relevante en Twitter. Además, la distribución geográfica de estos usuarios influyentes reflejó la dependencia cultural que tienen los deportes de nicho.

\section{Palabras clave}

AHP; ciclismo; deportes de nicho; eventos deportivos; usuarios influyentes; Twitter 


\section{Introduction}

Sport teams need communication to raise their public awareness. Mainstream media capitalise a good deal of this interest, as they reach a large audience. The development of digital channels has propitiated increasing access to sports information. User interaction is a key difference between the mass media, which provide clear top-down-oriented communication, and the digital media, which allow more horizontal communication. As users engage in the digital conversation, they help to spread information and create new content as a manifestation of a strong sense of belonging (Chan-Olmsted \& Xiao, 2019; Thompson, Martin, Gee \& Geurin, 2018; Vale \& Fernandes, 2018). This engagement can also be considered by sports teams as an asset to increase their financial value (Scelles, Helleu, Durand, Bonnal \& Morrow, 2017), promote brand sponsorship (Santomier, 2008) and attract spectators (Nisar, Prabhakar \& Patil, 2018). In a similar vein, social networks enhance the experience of attending sport events, providing event organisers and sports teams with new sources of information to help better understand their relationship with spectators, sports fans and sponsoring brands (Abeza, Pegoraro, Naraine, Séguin \& O'Reilly 2014; Delia \& Armstrong, 2015; Naraine, Schenk \& Parent, 2016; X. Wang, 2015).

Twitter has singular characteristics among the digital media. This social network provides quick interaction among users, and strongly contributes to the spread of information through viral mechanisms. In the context of sports communication, Twitter helps to get a picture of the main topics discussed by users (González et al., 2021; Huang, Shen \& Li, 2018; Méndez-Guzmán, Zhang \& Ahmed, 2021). The open conversation in Twitter allows us to explore how athlete branding unfolds over a period of time (SU, Baker, Doyle \& Kunkel, 2020), and the different way teams can build strong relationships with fans (Naraine, 2019; Wang, 2021). The way professional athletes, sport clubs, and amateurs take part in this online conversation has also been relevant (Hutchins, 2011; Kassing \& Sanderson, 2010). In particular, Twitter has modified the way TV spectators watch sport events, as this platform provides an immediate interaction with many other users who are following the same event simultaneously (Smith, Pegoraro \& Cruikshank, 2019; Yan, Watanabe, Shapiro, Naraine \& Hull, 2018).

In addition to these possibilities for broadening the experience of sport communication, Twitter opens up promising opportunities for minority sports. Mainstream media usually pay attention to sports that have a large spectator base, as their business model is based on the viewing figures. However, Internet in general, and Twitter in particular, make low-demand products and services accessible to those users interested in them. This phenomenon, known as long tail (Anderson, 2006), is perfectly suited to niche sports in Twitter.

According to Miloch and Lambrecht (2006), professional niche sports appeal to a small segment of sport consumers. Among the examples they provide we find lacrosse, bowling, fishing, curling, horse racing and archery. All of them were related to the US public, as the consideration of a sport as niche depends on the particular society to which it refers. Nevertheless, precisely because this sort of sport can be considered as a niche product, their athletes and followers are much more homogeneous than those sports. This feature is of great interest for sponsorship funding (Greenhalgh \& Greenwell, 2013; Greenwell, Greenhalgh \& Stover, 2013; Miloch \& Lambrecht, 2006). In terms of communication, social media is a key channel for the niche sport fan group, especially for information gathering and building communities, thanks to user interaction (Kang, Rice, Hambrick \& Choi, 2019). In the dynamics behind these platforms, information flows by interaction. In this regard, there is a particular group of users who boost this information flow in the network when they interact with the message, making content viral (Gross \& von Wangenheim, 2018; Tafesse \& Wood, 2021; Zhang, Moe \& Schweidel, 2017). Exploring how the Twitter conversation evolves requires the identification of this key group of users.

Although there are already several research works on the ways in which large sport teams and mass sporting events (such as the Olympic games or world soccer championships) leverage social networks (Abeza et al., 2014; Clavio, Walsh \& Vooris, 2013; Jensen, Limbu \& Spong, 2015; Méndez-Guzmán, Zhang \& Ahmed, 2021; Y. Wang, 2021; Yu \& Wang, 2015), in the case of niche sports the research is much more limited (Mastromartino, Qian, Wang \& Zhang, 2020; Trivedi, Soni \& Kishore, 2021). Our study helps fill this gap by analysing the Twitter conversation during the 2018 UCl Track Cycling World Championships. This competition is the most important event in track cycling, but the sport can be considered niche, as its media coverage is much less widespread than road cycling, as would be the case of the Tour de France.

This research explores the main profiles of the more influential Twitter users during an international event of a niche sport. To tackle this problem, we developed an influence index based on six variables. Some of them are taken from the direct participation of the user, and the rest from social interaction. We composed this index based on a novel methodology in digital communication research: Analytic Hierarchy Process (AHP) (Lamirán-Palomares, Baviera \& Baviera-Puig, 2020). This technique establishes a weight for a series of variables based on the judgements of a group of experts. AHP is particularly appropriate for this problem, as it allows us to quantify the attributes of a complex phenomenon such as influence in Twitter. The process ensures consistency among the opinions collected, so that the output can be considered 
reliable according to the group of experts. Once we had drawn up the index, we applied it to the case of the $2018 \mathrm{UCl}$ Track Cycling World Championships, a niche sport among cycling modalities.

The paper is structured as follows. The theoretical framework reviews the literature on influence on Twitter, the Social Network Analysis (SNA) applied to Twitter, and niche sports. After that, we briefly introduce the $2018 \mathrm{UCl}$ Track Cycling World Championships. Then, the research objectives are presented. Next, the research methodology is outlined, where the AHP stands at the core of the process. Subsequently, the results are presented and discussed. The paper ends by pointing out some limitations to our research.

\section{Theoretical framework}

\subsection{Influence on Twitter}

The dynamics of digital communication have different parameters from those of the traditional media, whose main indicator is the audience. On Internet, the logic of network communication bestows great power on users whose intervention propels dissemination of the message. This action can be considered as part of its influence in the network. Influence can be considered broadly as the ability of an individual to make others change their attitude, opinion, or commentary (Dubois \& Gaffney, 2014). In this regard, social networks create special conditions for influencing due to the interactions of the users. Nevertheless, identifying a user as influential becomes complicated. Some theories help to explain different aspects of how this influence can be conceived.

Agenda setting theory (McCombs \& Shaw, 1972) explains the capacity of mass media to determine the news items that are of informative interest. Depending on the way they present the content, mass media play a role in attributing different levels of importance to them. This way of influencing is focused on the content, and is explained by the prescriptive role exerted by mainstream media. With the arrival of social media, this role has had to be shared, at least partially, with other agenda-setters (BiascoDuatis \& Coenders, 2020). As Rubio García (2014) states, there is a strong correspondence between the media agenda and the public agenda reflected in Twitter.

Another relevant conceptualisation to characterise the process of media influence was the twostep flow theory (Katz, 1957). This theory underlined the bridging role that certain individuals played between the media and the public, so that these individuals could be considered as prescribers of the information published by the media. These individuals were designated opinion leaders and were initially characterised by having a wide network of contacts, being considered experts on a specific topic, and having a relevant position within a local community. In this case, influence is exerted by way of personal interaction. The advent of Internet revived this two-step communication model, which had been weakened by the direct effect of television. Veglis and Maniou (2018) suggested an evolution from the two-step theory to a model of communication flows where the role of intermediation with the network of contacts becomes crucial when analysing influence.

The possibility of tracking the interactions and the content published in social media has prompted research to identify the key actors in disseminating messages (Denia, 2021). Researchers have used different metrics to identify influential Twitter users with the aim of assessing their position within the structural network. Kwak, Lee, Park \& Moon (2010) ranked users according to the number of followers and also added the PageRank variable, which was originally used in web positioning (Page \& Brin, 1998). Bakshy, Mason, Hofman y Watts (2011) linked the influence to the follower base and the time active in Twitter, but suggested that users with a smaller base could be more effective for marketing campaigns. GonzálezBailón, Borge-Holthofer \& Moreno (2013) focused on user activity, counting their Twitter messages over a period of time, and identified four types of different users. Lara-Navarra, López-Burrull, Sánchez-Navarro \& Yànez (2018) presented different instruments used to measure influence in social media.

In sport communication, different studies have analysed some Twitter profiles that can operate as influential in the conversation. Athletes have been the subject of some of these studies, in many cases leading them to be seen as "celebrities" (Kassing \& Sanderson, 2010; Pegoraro, 2016). Other sport-related users whose activity on Twitter has also been analysed include journalists (Hambrick \& Sanderson, 2013), sponsors (Meenaghan, Mcloughin \& McCormack, 2013) and event organisers (Hambrick, 2016; Wäsche, 2015). Focusing on influence, other studies have already attempted to identify influential users on Twitter in different sports (Blaszka, Burch, Frederick, Clavio \& Walsh, 2016; Hambrick et al., 2016; Naraine, Schenk \& Parent, 2016). For Gayo-Avello (2013) and Bouguessa \& Romdhane (2015), there is no clear consensus on the variables to be used to measure influence in Twitter. Albero-Gabriel (2014) highlighted the convenience of taking as main indicators the number of followers, the number of retweets and the number of mentions. Cha, Haddadi, Benevenuto and Gummadi (2010) pointed out that a large number of followers is related to the popularity of the profile and has its significance in the number of mentions, while the number of retweets is conditioned by the interest of the tweet. Hence, we see that there are multiple ways of ranking influence based on the inclusion or exclusion of different variables. 
Influence in Twitter comprises multiple approaches, as it is difficult to capture in just one measure. One methodology that has proved to be very useful for featuring Twitter conversations is Social Network Analysis (SNA). This methodology studies the interaction among social agents (Scott, 2017; Wasserman \& Faust, 1994). The social relationships are usually represented in a graph. This figure is composed of nodes, which represent the social agents, and edges, which represent the interactions between two agents. A node will be more important if it plays a relevant role in the interaction (de Nooy, Mrvar \& Bategelj, 2005). This relevance corresponds to the concept of centrality. Two basic measures of centrality are the indegree of a node (the number of interactions initiated by that node) and the outdegree (the number of interactions directed to that node).

SNA methodology is very well suited to the relationships created through posting in Twitter, as there are some activities, such as following, retweeting, and mentioning, that can be considered interactions in terms of SNA (Clavio, Walsh \& Vooris, 2013; Sanderson \& Hambrick, 2016; Wäsche, Dickson, Woll \& Brandes, 2017).

Dubois \& Gaffney (2014) compared the degree of agreement of six Twitter metrics, so that different facets of influence could be identified. Most of the metrics were standard SNA measures, such as indegree, eigenvector centrality and clustering coefficient. Riquelme \& González-Cantergiani (2015) covered the extensive literature on the ways in which Twitter influence has been evaluated. They classified the metrics into three broad categories: activity, popularity, and influence. They considered users influential in Twitter if they participated frequently by posting, if they were recognised by the community, and if their actions in the platform affected the activity of other users. Many of the metrics collected by Riquelme \& González-Cantergiani (2015) were related to SNA.

We consider influence in Twitter in a restricted way: the capacity of a user to spread information in a significant manner and the presence of a user in the content of the online conversation. Following the categories proposed by Riquelme \& González-Cantergiani (2015), we articulated this capacity in three dimensions: activity, authority, and popularity. A user can be influential: i) if their participation in the Twitter conversation is frequent (activity dimension); ii) if the tweets they post provoke the interaction of other relevant users in the conversation (authority dimension); and iii) if they enjoy the recognition of other users (popularity dimension) (Lamirán-Palomares, Baviera \& Baviera-Puig, 2020).

To construct our model, we selected two variables related to each of the three dimensions identified, with the aim of quantifying the phenomenon of influence in Twitter. In total, we had six variables. Although it is not easy to find neat boundaries to classify the variables, the dimensions helped us select the appropriate metrics to assess the user influence. Three of these variables correspond to the direct posting by the Twitter user, whereas the other three variables come from considering the Twitter interaction in terms of SNA, i.e., retweeting and mentioning.

The six variables are as follows. User activity is reflected in the number of tweets posted by a user (González-Bailón, Borge-Holthofer \& Moreno, 2013). More tweets imply a more participative user. Tweets can be just a message, in plain text, or may contain a reference to another user. This is the case when retweeting a tweet or mentioning a user. The way of measuring this referential activity is by looking at the outdegree of the node. A user can be considered endowed with authority if their tweets are retweeted. So, the number of retweets of a user would be a way of indicating peer acknowledgement of the worth of their publications (Albero-Gabriel, 2014; Cha et al., 2010). In terms of SNA, the authority of a user is captured by the PageRank metric. This measure ranks higher when a user is linked by other users who in turn have high PageRank. Therefore, PageRank provides a measure of the density of the interaction relationships. This means that if a high PageRank user intervenes in a conversation, it is much more likely that the message will spread more quickly than if another low-PageRank user intervenes (Dubois \& Gaffney, 2014; Kwak et al., 2010). Finally, popularity can be assessed by looking at the number of followers of a user (Albero-Gabriel, 2014; Cha et al., 2010; Kwak et al. (2010). From the interaction perspective, popularity can be evaluated through the indegree of a node, i.e., the number of mentions and retweets received by a user (Albero-Gabriel, 2014; Cha et al., 2010; Dubois \& Gaffney, 2014).

\subsection{Niche sports and social media}

Niche sports are characterised by their reduced audience (Miloch \& Lambrecht, 2006). The specific interest aroused by this kind of sport make it very appropriate for leveraging the long-tail dynamics (Anderson, 2006): social media bring together supporters and enthusiasts that otherwise would be unattended by mainstream mass media. The interest in researching niche sports has been linked to the special possibilities provided to sponsoring brands (Miloch \& Lambrecht, 2006). Greenhalgh and Greenwell (2013) asked more than 30 sponsors about the criteria they used to select which niche sports they would promote. Audience reach, cost-effectiveness, and the fit between company image and target market were positioned as the main criteria, whereas social media opportunities were ranked among the least important criteria for investment. 
Recently, some researchers have examined specific ways of social media communication about niche sports. Kang et al. (2019) analysed three marketing activities in the context of CrossFit, a niche sport with scant media coverage in the US. They examined Twitter, Facebook and YouTube posts. According to these researchers, these platforms were used primarily to provide information and to interact with the community, but they detected less content regarding product promotion. Trivedi, Soni \& Kishore (2021) conducted a study about the pro-Kabaddi league, a minority sport in India. They comprised three activities as social media communication: user-generated content, firm-generated content and social media ads. The results proved the influential role played by social media communication in boosting fans' online community engagement, and subsequently in game attendance and sponsor's product purchase intention. Mastromartino et al. (2020) analysed the factors influencing socialisation of ice hockey fans in the Sunbelt region of the US. This sport began to appear there 25 years ago. These researchers found evidence that the ways the fan-base socialise were departing from traditional sources, as they were through family and media exposure. The paper suggests that this change may be due to the access to communication technology by the new generation. Nevertheless, there is scant attention paid to the specific way information flows in Twitter regarding niche sports through prominent users. This point may be of great interest for event organisers, brand sponsors and sports teams.

\subsection{The 2018 UCI Track Cycling World Championships}

Track cycling is a modality of bicycle racing mainly oriented to professional bikers. Races take place in velodromes, special arenas designed for cycling at high speed. Track bicycles are characterised by having a fixed gear and lacking brakes. They are designed to reduce resistance as much as possible to increase velocity. Unlike road cycling, track cycling competitions are much less viewed by media audiences, so it can be considered a niche sport.

The UCI Track Cycling World Championships are the most important event in this niche sport. They are held annually by the International Cycling Union (UCl in French). Professional and amateurs compete together, representing their countries. These championships encompass several events, such as time trial, individual pursuit, team pursuit or scratch race. There are races for women and races for men. The winning rider is distinguished by the $\mathrm{UCl}$ with a rainbow jersey. The 2018 edition took place in Apeldoorn, the Netherlands, from 28 February to 4 March. There were 40 competing nations, and 20 events. The medal table was headed by the Netherlands, the host country, with 12 medals. Germany, Great Britain, Australia, and Italy achieved 6 medals in the championships.

\section{Research objectives}

This aim of this research is to analyse in depth the impact of Twitter in a niche sport. The key issue structuring the whole research process is the concept of influence in social networks. Based on this assumption, three main objectives were set:

01: To draw up an index to measure Twitter influence for each user participant in the conversation based on the following variables: number of tweets, outdegree, number of retweets, PageRank, number of followers and indegree.

O2: To identify the most influential users in the Twitter conversation about the $2018 \mathrm{UCl}$ Track Cycling World Championships.

O3: To analyse the contribution of the most influential Twitter users to the event from the approach of being a niche sport.

\section{Methodology}

\subsection{Analytic Hierarchy Process}

The AHP was designed by Saaty (1980) and has been applied in the resolution of a wide variety of problems, including sports-related questions (Lee \& Walsh, 2011; Sinuany-Stern, 1988). AHP requires a group of experts to evaluate the importance of different criteria to solve a given problem. Its basic principle assumes that the experience and knowledge of the experts involved is as important as the data, so it is used in problems where both quantitative and qualitative aspects need to be assessed. The goal is to prioritise a series of items. The AHP allows structuring of the items in different levels. In the case of having two levels, the process distinguishes between criteria and subcriteria, in such a way that there is a group of subcriteria depending on each criterion.

The experts prioritise the different items by filling in a questionnaire. Each question always compares two items. The respondent scores each pair of items from one to nine, where one means the same importance of both items, and nine means extreme importance of one item over the other one. First, all the criteria are compared in groups of two. Then, the questionnaire asks for the subcriteria pertaining to the first criterion, following the same approach of pairing the items. The following question asks the 
importance of the subcriteria associated to the second criterion, so that the process continues in this way to cover all the criteria with their respective subcriteria. AHP goes beyond a mere sorting of items, as it integrates several hierarchical levels (criteria and subcriteria) and takes into account the degree of relevance between two items considered by the experts (qualitative estimation). This leads us to the critical contribution of the process.

One matrix is created with the peer-to-peer comparisons made by each expert. All the matrix elements are positive and verify the property of reciprocity (Saaty, 1980). However, the matrix does not necessarily comply with the property of consistency, as the expert's judgements are subjective (MarinGarcía, Aragonés-Beltrán \& García Melón, 2014). To verify this property, the consistency ratio must be calculated. This ratio reflects how consistent the judgements made by one expert are on the whole. The ratio is compared with a reference value that varies according to the size of the matrix (Saaty, 2008). Following Marin-García, Aragonés-Beltrán \& García Melón (2014), our threshold for the consistency ratio was set at $10 \%$. Values lower than $10 \%$ mean that the successive judgements made by the expert have been consistent throughout the process, so that their comparisons can be considered reliable. Values higher than $10 \%$ reflect that the expert's judgements lack consistency, and, therefore, that this evaluation should be reviewed or discarded. In order to merge the validated judgements into a single judgement representative of the entire group, the geometric mean is used. Saaty (2008) recommends this method, as it maintains the reciprocity property of comparative judgements.

In our case, the dimensions of the influence (activity, authority and popularity) play the role of AHP criteria, while the variables we have identified as critical for measuring influence in Twitter correspond to the AHP subcriteria (number of tweets, outdegree, number of retweets, PageRank, number of followers and indegree). Figure 1 presents the integration in the AHP methodology of the hierarchical relationships between influence dimensions and influence variables.

The AHP questionnaire initially provided a brief description of the items we wanted to prioritise, i.e., the criteria and the subcriteria. The question for the criteria was posed as follows: "Which of these two alternatives do you estimate is more important when considering the influence of a user in Twitter? If you estimate one alternative more relevant than the other, please state the degree of importance ranging from one (equally important) to nine (extremely more important)." An example of the scale for evaluating one pair of criteria was: "Authority 975313579 Activity". An example of a question regarding a couple of subcriteria was: "Which of these two variables do you estimate is more important when considering the activity of an influential user in Twitter? If you consider that one alternative is more relevant than the other, please indicate the degree of importance ranging from one (equally important) to nine (extremely more important)." The scale presented to the respondent was as follows: "Number of tweets 975313579 Outdegree". The questionnaire ended up by asking about sociodemographic variables.

The experts who answered the questionnaires were fifteen intensive Twitter users. Ten of them worked in marketing, media and communication agencies of different sizes, and $80 \%$ of them collaborated in universities providing training in digital marketing. Fourteen of them had college degrees and five of them were PhDs.

Figure 1. AHP structure process used to assess Twitter influence

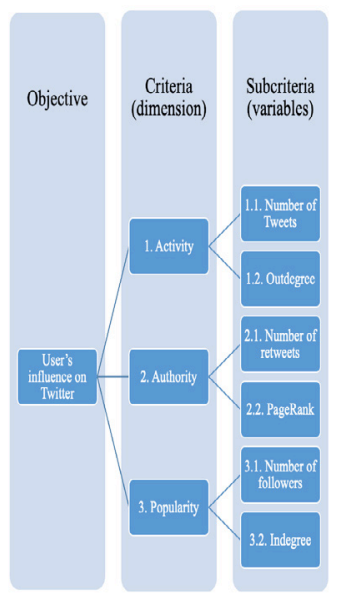

Source: own creation. 


\subsection{Corpus and variables}

The dataset was built by collecting the tweets that included the Championship official hashtag \#Apeldoorn2018. The extraction period extended from February 28 to March 4. We employed Audiense software. The size of the resulting corpus was 19,701 tweets. They had been posted by 7,281 different users. We obtained the number of tweets, the number of followers and the number of retweets for each user directly from the dataset. To evaluate the indegree, the outdegree and the PageRank for each user, we first drew up the graph of the interaction among the users registered in the dataset, and then we evaluated those variables with Gephi (Bastian, Heymann y Jacoby, 2009), a popular software for SNA.

\subsection{Research process}

The main research objective was to identify the influential users based on the selected variables after revising the academic literature. To construct a unified measure of influence, we carried out the expert consultation according to the AHP methodology. The output of this process provided the weight for each variable.

Next, we estimated the variables involved for all the users present in the dataset. Given the variables and the corresponding weights, we assessed the degree of influence of each user according to this function:

$$
\begin{aligned}
\text { Influence Index } & =C_{11} * \text { Number } \widehat{\text { of Tweets }}+C_{12} * \text { Out } \widehat{\text { Oegree }} \\
& +C_{21} * \text { Number } \\
& +C_{31} * \text { Number } \text { of Retweets }+C_{22} * \text { Pallowers }+C_{32} * \text { Indegree }
\end{aligned}
$$

, where $\mathrm{C}_{\mathrm{ii}}$ corresponds to the weight of the j subcriterion of the i criterion. Each variable was normalised over the sum of all the values. In this way, the influence index is a number between 0 and 1 , and the sum of all the influence indexes must be 1 .

This unified measure allowed us to sort all the users according to their degree of influence. This way, the 25 most influential users were identified. Finally, the top 25 users were categorised into seven groups, according to their profile: 1 = Participating athlete; 2 = Media; 3 = Amateurs; 4 = Cycling-related media; 5 = Journalists, bloggers and content creators; $6=$ Cycling-related institutions (federations, event organisation); 7 = Others. Figure 2 summarises the research process.

Figure 2. Methodological approach

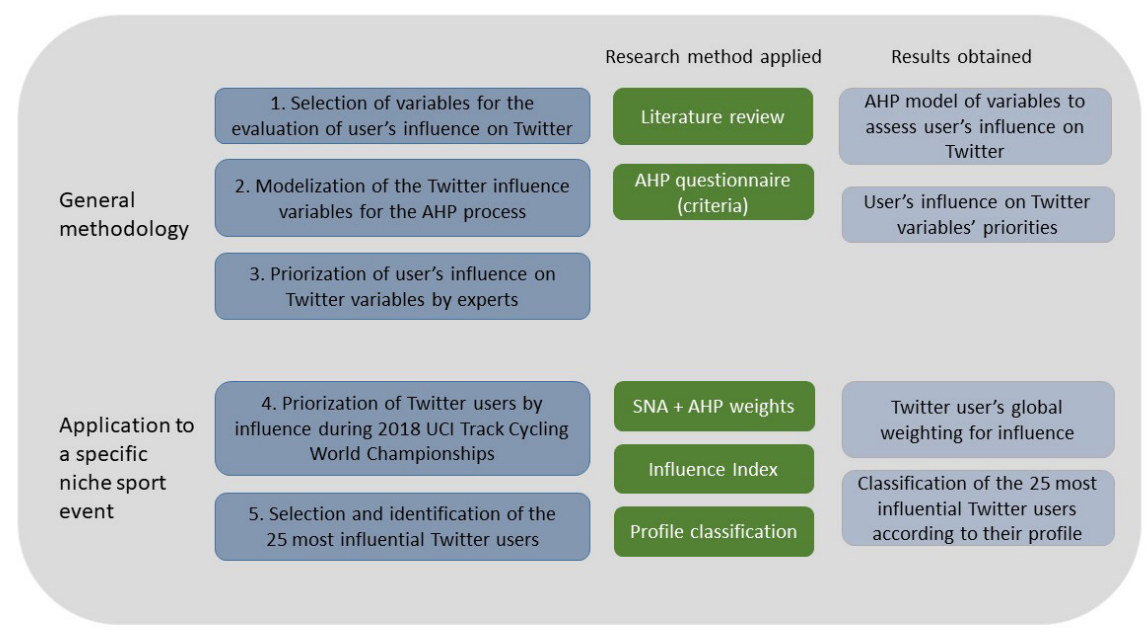

Source: own creation based on Baviera-Puig, García-Melón, Ortolá \& López-Cortés (2021).

\section{Results}

\subsection{Model of Twitter user's influence estimated by experts}

The consulted experts completed the questionnaires with the peer-to-peer comparisons. Consistency ratios were calculated for each questionnaire as AHP prescribes. Three out of the fifteen questionnaires had to be discarded, as they obtained a consistency ratio higher than $10 \%$. With the results of the 
validated questionnaires, the geometric mean was calculated, as recommended by Saaty (2008), to obtain a single representative judgement of the whole group.

Table 1 shows the weights of the subcriteria that assess the influence of a user on Twitter according to the experts consulted. The most important subcriteria or variables when evaluating Twitter user influence were the number of retweets $(37.28 \%)$, PageRank $(24.75 \%)$ and indegree $(20.17 \%)$. The less important were the number of tweets (3.22\%), outdegree (5.16\%) and number of followers $(9.42 \%)$. In terms of criteria, the influence dimension of authority obtains the highest weight, as the criterion value represents the sum of the respective weights of the dependent subcriteria.

The first stage of the methodology ended by obtaining these weights. This was the generic stage; thus, the list of subcriteria and their weights can be used in any Twitter user's influence prioritisation process, regardless of the type of issue being evaluated. In the next section, we will apply these results to the 2018 UCI World Track Cycling Championship to find out the most influential users during this event.

Table 1. Weights of the criteria and subcriteria that determine a user's influence on Twitter

\begin{tabular}{ccc} 
Criteria & Subcriteria & Weight (\%) \\
\hline \multirow{2}{*}{ C1. Activity } & C11. Number of tweets & 3.22 \\
& C12. Outdegree & 5.16 \\
C2. Authority & C21. Number of retweets & 37.28 \\
& C22. PageRank & 24.75 \\
C3. Popularity & C31. Number of followers & 9.42 \\
& C32. Indegree & 20.17 \\
& TOTAL & 100.00
\end{tabular}

\subsection{Centrality measures}

Gephi provided the centrality measures for each user registered in the dataset: outdegree, indegree and PageRank. Figure 3 shows the graph of Twitter users' interaction during the studied event. The node size represents the outdegree measure. The colours show the different clusters or groups identified by Gephi. Clusters reflect users who are grouped by close interactions. One of the reasons for this proximity is nationality. Thus, for example, the profiles of Colombian cyclists and their followers are included in the same green group and speak the same language (Spanish). The profiles that describe Spanish cyclists are coloured orange, and the British in blue. The peripheral positions influence neighbouring clusters, while the central positions reach a greater number of users. This figure synthesises the conversation to identify the relative position of the users in the global interaction. Now, we proceed to use the AHP results to find out the most influential users in this interaction.

Figure 3. Twitter interaction graph of the event with the hashtag \#Apeldoorn2018

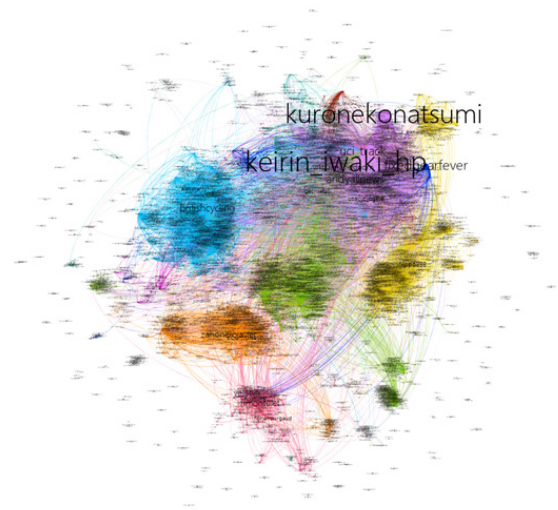

Source: own creation. 
Table 2. The 25 most influential Twitter users with breakdown by variables and profile categories

\begin{tabular}{|c|c|c|c|c|c|c|c|c|c|}
\hline & User & Tweets & Followers & RT & Ind & Outd & PR & $\operatorname{lnf}(\%)$ & $\mathrm{PC}$ \\
\hline 1 & UCl_Track & 294 & 14,178 & 3,672 & 2,087 & 73 & 0.05874 & 23.302 & 6 \\
\hline 2 & BritishCycling & 161 & 156,532 & 1,189 & 818 & 47 & 0.01803 & 7.936 & 6 \\
\hline 3 & fedeciclismocol & 22 & 36,990 & 503 & 395 & 8 & 0.01180 & 3.740 & 6 \\
\hline 4 & Eurosport_IT & 27 & 73,342 & 511 & 339 & 6 & 0.01074 & 3.567 & 2 \\
\hline 5 & Federciclismo & 47 & 25,907 & 350 & 339 & 20 & 0.01015 & 2.987 & 6 \\
\hline 6 & fabianpuerta 141 & 3 & 17,318 & 0 & 674 & 5 & 0.01598 & 2.683 & 1 \\
\hline 7 & BBCSport & 6 & $7,250,358$ & 11 & 40 & 6 & 0.00207 & 2.647 & 2 \\
\hline 8 & FFCyclisme & 86 & 18,543 & 402 & 145 & 24 & 0.00656 & 2.499 & 6 \\
\hline 9 & JuanManSantos & 1 & $5,298,442$ & 60 & 61 & 1 & 0.00400 & 2.393 & 7 \\
\hline 10 & RFECiclismo & 97 & 24,890 & 348 & 174 & 21 & 0.00605 & 2.317 & 6 \\
\hline 11 & JCF_cycling & 79 & 15,508 & 449 & 144 & 3 & 0.00359 & 2.315 & 6 \\
\hline 12 & ClaraLuzRoldan & 1 & 26,023 & 222 & 222 & 0 & 0.00697 & 1.888 & 5 \\
\hline 13 & ItaliaTeam_it & 6 & 51,811 & 219 & 166 & 0 & 0.00675 & 1.755 & 6 \\
\hline 14 & TeamGB & 17 & 928,775 & 234 & 143 & 13 & 0.00257 & 1.728 & 6 \\
\hline 15 & mundociclistico & 17 & 37,116 & 260 & 204 & 8 & 0.00318 & 1.697 & 4 \\
\hline 16 & SebastianMoraV & 7 & 2,187 & 150 & 277 & 7 & 0.00603 & 1.681 & 1 \\
\hline 17 & carlosvives & 1 & $4,988,539$ & 0 & 0 & 1 & 0.00004 & 1.60 & 7 \\
\hline 18 & chloedygert30 & 8 & 4,619 & 0 & 305 & 10 & 0.00852 & 1.43 & 1 \\
\hline 19 & alberttorresb & 36 & 3,135 & 64 & 229 & 39 & 0.00595 & 1.41 & 1 \\
\hline 20 & gannafilippo & 8 & 2,938 & 0 & 290 & 9 & 0.00753 & 1.308 & 1 \\
\hline 21 & maximilianlevy & 8 & 2,968 & 0 & 246 & 9 & 0.00662 & 1.136 & 1 \\
\hline 22 & Coninews & 5 & 236,970 & 151 & 140 & 2 & 0.00226 & 1.121 & 6 \\
\hline 23 & Japan_Olympic & 1 & 399,065 & 104 & 102 & 0 & 0.00321 & 0.999 & 6 \\
\hline 24 & usacycling & 13 & 59,591 & 53 & 162 & 14 & 0.00409 & 0.971 & 6 \\
\hline 25 & wkbaanapeldoorn & 85 & 947 & 46 & 123 & 34 & 0.00395 & 0.966 & 6 \\
\hline
\end{tabular}

Notes:

RT: Retweets. Ind: Indegree. Outd: Outdegree. PR: PageRank. Inf (\%): Normalised Influence (\%). PC: Profile Category.

Profile category: 1 = Participating athlete; 2 = Media; 3 = Amateurs; 4 = Cycling-related media; $5=$ Journalists, bloggers, and content creators; $6=$ Cycling-related institutions (federations, event organisation); 7 = Others.

\subsection{Most influential users}

The influence is assessed for every user according to the six variables measured (number of tweets, outdegree, number of retweets, PageRank, number of followers and indegree) and the weights provided by the AHP process. This index allows sorting of all the 7,281 users. Table 2 shows the top 25 influential users according to our influence assessment, and includes their profile classification. 
Observing the 25 most influential users, we find: six athletes, five men and one woman (category 1); thirteen related somehow to the event, such as organisations and federations (category 6); two mass media (category 2), and four from other categories (4 and 7). It should be noted that the first three positions, UCl_Track, BritishCycling and fedeciclismocol (the Colombian Cycling Federation), as well as the fifth, (FederCiclismo) belong to the same category (6). It is also important to note that the local event organiser account, wkbaanapeldoorn, appears in position 25.

The next most important user group is that of the athletes. Colombian Fabián Puerta, the Spaniards Sebastián Mora and Albert Torres, Italian Filippo Ganna and German Maximilian Levy stand out in this group. The only woman who appears in this ranking is Chloe Dygert, from the USA.

Finally, we have another six users, two from generalist media, Eurosport from Italy and the BBC, which were two media that broadcast the event, and four from two different groups. These were three public figures: Juan Manuel Santos (Colombian President), Carlos Vives (Colombian singer) and Clara Luz Roldan (Colombian politician), as well as a specialised medium (Mundo Ciclístico magazine). These four users have in common that their origin is Colombian.

If we analyse the outcomes by country of origin, we see that the country with the highest number of users in this ranking is Colombia, with six positions. Italy comes the next with five users, followed by the United Kingdom and Spain with three, and finally the United States, Japan and France with two users each.

\section{Discussion}

The aim of this research was to study the conversation dynamics in Twitter during a niche sport event. The backbone of the research is the concept of influence. In particular, we are interested in characterising the professional profiles of those users who stand out due to their capacity to spread information through the interaction network and to their status as a reference in the conversation. This is even more relevant when analysing the case of a niche sport, as its public impact is much more reduced because of the scant or null mass media coverage. In this case, we focused on the $2018 \mathrm{UCI}$ World Track Cycling Championships and the conversation generated in Twitter containing the hashtag \#Apeldoorn2018.

The first objective (O1) was intended to build a measurement for assessing the influence in Twitter. This phenomenon was considered from three perspectives or dimensions: activity, authority and popularity of the user. For each dimension, we pick two variables that could serve as a metric for that aspect. All six variables provided useful information on the impact of the user's influence in the Twitter conversation. For this reason, AHP methodology was employed, as it allows researchers to draw up an index combining different weighted variables. The AHP output provides the weights based on the nuanced judgements of an expert panel, and the procedure assures that those qualitative opinions are consistent.

According to the experts consulted for this research, the results of the AHP process highlighted the relevance of considering authority dimension (62\%) over popularity $(29.6 \%)$ and activity $(8.4 \%)$ of a particular user to be considered as influential in Twitter. Looking at the variables involved, the global opinion given by the experts allocated $37.28 \%$ of the weighting to the number of retweets $24.75 \%$ to the PageRank and $20.17 \%$ to the indegree measure. This result suggests, on the one hand, the importance of the content for being considered as influential, as we can assume that high-quality messages will be shared by a greater number of users. On the other hand, we can infer the advantage of being referenced by other users who are well referenced in the whole interaction network at the same time. The other three variables reached smaller weights: $9.42 \%$ for the number of followers, $5.16 \%$ for the outdegree metric and $3.22 \%$ for the number of tweets. Therefore, in our model we could say that influence is, at an essential level, a phenomenon linked more with quality than quantity. In other words, activity alone does not create influence, but rather the quality of one's influence (understood as part of the authority and popularity dimensions).

The weights obtained in the AHP procedure allowed us to identify the top 25 influential users who tweeted about the $2018 \mathrm{UCl}$ Track Cycling World Championships celebrated in Apeldoorn during the first days of March (O2). The two most prominent user profiles in this classification are the sport organisations and the athletes. However, Hambrick, Simmons, Greenhalg \& Greenwall (2010) and Naraine, Schenk \& Parent (2016) considered that the event organiser and sport journalists would exert an influential role in the Twitter conversation during sport events. In our case, in the first position we find the main organiser user, the UCl_Track, which is by far the most influential user (23.3\% of normalised influence, whereas the next user has $7.9 \%$ ). It posted the most (294 tweets), and its follower base was medium sized compared with the rest of the table $(14,178)$. The fact of being a niche sport made this contribution more valuable. However, we did not find any journalists in the top 25. Instead, the classification revealed two mainstream media (Eurosport_IT and BBCSport), one specialised magazine (mundociclistico) and three public figures (JuanManSantos, ClaraLuzRoldan, and carlosvives). This lack of journalists could be explained precisely because we are dealing with a niche sport. 
It should be noted that the greater or lesser influence of these top 25 users is not always related to the number of medals achieved in the races. The Netherlands led the final medal count with 12 medals and was also the host country, but this did not translate into a higher number of users from this country among the 25 most influential users. In fact, the local event user wkbaanapeldoorn appears in position twenty-five and it is the only one belonging to the Netherlands in Table 2. In contrast, Colombia won only one medal, and yet there are 6 users of Colombian origin in the ranking. These are the two extreme cases. In the intermediate situations, we find Italy, United Kingdom, Spain, the United States, Japan and France. Athletes from these countries won medals, and in addition Twitter users from these countries were ranked among the most influential ones during the event. This unbalanced situation could be explained because in the Netherlands, track cycling is considered a niche sport. But this is not the case with Colombia, where cycling is much more popular. This fact shows how the consideration of a sport as niche or not depends on the national culture in which it takes place (Miloch \& Lambrecht, 2006).

These outcomes could confirm the relevant role played by cycling-related institutions, e.g., federations and associations (category 6), in promoting the Twitter conversation about the event. Yan et al. (2019), in their research into the UEFA Champions League Final, obtained a similar result when they identified the prominence of large sports entities in the Twitter network structure. In their case, it was the Champions League that held a privileged position in the ranking. Therefore, we can see how this group is relevant both in large sporting events and in niche sports. In this sense, the strategic management of social media by this type of institution is a fundamental communication resource.

The participating cyclists (category 1) are another group with a strong presence in the list of top influential users, and therefore their role as catalysers of the online conversation could be considered transcendental. This suggests that the ranking position could be a consequence of their sporting outcome and of their activity or mention-receiving in Twitter. In this regard, the role that Twitter could play as a means of amplifying the sport results obtained by the athletes would be very important in terms of future personal promotion. These results are consistent with those obtained by Kang et al. (2019) for niche sports. They also found that, despite their relevance in the digital conversation, both kind of actors (categories 1 and 6) did not take advantage of promotional opportunities compared to interaction and information opportunities. It is worth mentioning that all the athletes positioned in this ranking won a medal during the championship, and it is remarkable that in this classification no athlete from the organising country (the Netherlands) appears, when there were several who were present in the medal registry and had user accounts in Twitter also.

The scenario for this study was a niche sport (O3). In addition to the cultural differences among the tweeting communities and the invigorating role played by the event organiser, Table 2 highlights the key presence of public figures in the conversation. The Colombian individual users tweeted just once, and they were regarded as an influential actor in the conversation by our index. Two of them had a very significant follower base (JuanManSantos with 5.3M and carlosvives with $5 \mathrm{M}$ ). The participation of celebrities always has a strong impact, which is even more evident in the case of a niche sport. Although digital communication has helped promote niche sport fandom (Mastromartino et al., 2020), the main actors in the Twitter conversation around niche sports are organisations and mainstream media. This salience makes it difficult for niche sport sponsors to invest in social media (Greenhalgh \& Greenwell, 2013).

The classification of user profiles into different categories according to origin, profession or sporting results gives our research significant added value by transferring the scope of events to a global digital environment. This suggests that social media influence spans traditional boundaries and expands the reach of events to a broad digital sphere. This could be particularly relevant for event organisers and athletes of niche sports in their digital communication strategy.

\section{Limitations and future lines of research}

One limitation of our research is that it does not consider the dynamic nature of social media. The temporal dimension could also be included in future research to compare the interaction network in different time periods (before, during and after the event) as Abeza et al. (2014) did. In this regard, it would be useful to analyse the network evolution throughout the duration of the event. Other important limitation is the expert panel and its size. The research results depend on this consultation. One way to improve this research outcome would be to expand the group of experts. At least this study has proved the utility of applying AHP methodology to the problem of quantifying influence.

As future lines of research, it could be interesting to compare these results with another sporting event (World Cup or European Championships), to determine whether the most influential users follow the same pattern as this research. In this way, the conclusions that refer to the grouping by categories of the different users or the geographical origin of the accounts and their relationship with the sports results obtained could be verified. Another line of research would be to analyse the scope of the Twitter 
posts of the different influential users over their communities. In this way, the impact could be better estimated, both in terms of media coverage and sponsorships, either of the event itself or of a particular athlete. Finally, further research could test whether these results could also be useful for other social networking sites, such as Facebook or Instagram.

\section{Conclusions}

Influence in Twitter is constructed from a variety of perspectives. Following the AHP methodology, we were able to draw up an index for assessing the relative degree of influence of a user who participates in a Twitter conversation. Aspects more related with quality rather than quantity were rated better by the experts consulted. The variables referring to authority (number of retweets and PageRank) were considered to feature more important Twitter influence than those referring to activity (number of tweets and outdegree).

This influence index was applied to Twitter conversation during the $2018 \mathrm{UCl}$ Track Cycling World Championships. The fact that it is a niche sport enabled us to delve into the digital communication around a lower-demand sport. The global conversation confirmed the cultural dependence of this kind of sports. In addition, the top 25 influential users were shaped by cycling organisations, athletes, media and public figures.

Although influence is a contextualised and complex phenomenon, the use of AHP provided a useful tool for identifying the most influential users on Twitter. This list helped to approach a niche sport with the aim of determining more accurately who leads the online conversation. In this regard, our research reveals the important role that social media can play when promoting a niche sport without opportunities for consideration in the traditional media. If a proper strategy is developed through the right social media influencers, it can make a significant impact.

\section{References}

[1] Abeza, G.; Pegoraro, A.; Naraine, M. L.; Séguin, B. \& O'Reilly, N. (2014). Activating a global sport sponsorship with social media: An analysis of TOP sponsors, Twitter, and the 2014 Olympic Games. International Journal of Sport Management and Marketing, 15(3-4), 184-213.

http://dx.doi.org/10.1504/IJSMM.2014.072010

[2] Albero-Gabriel, J. (2014). Twitter, \#primaveravalenciana y generación de noticias. CIC Cuadernos de Información y Comunicación, 19(0), 253-269. http://dx.doi.org/10.5209/rev_ciyc.2014.v19.43914

[3] Anderson, C. (2006). The Long Tail: Why the Future of Business is Selling Less of More. New York: Hyperion.

[4] Bakshy, E.; Mason, W. A.; Hofman, J. M. \& Watts, D. J. (2011). Everyone's an influencer: Quantifying influence on twitter. In Proceedings of the 4th ACM International Conference on Web Search and Data Mining, WSDM 2011 (pp. 65-74). http://dx.doi.org/10.1145/1935826.1935845

[5] Bastian, M.; Heymann, S. \& JACOMY, M. (2009). Gephi: An open source software for exploring and manipulating networks. In International AAAI Conference on Weblogs and Social Media (pp. 361-362).

[6] Baviera-Puig, A.; García-Melón, M.; Ortolá, M. D. \& López-Cortés, I. (2021). Proposal of a New Orange Selection Process Using Sensory Panels and AHP. International Journal of Environmental Research and Public Health, 18(7), 3333. http://dx.doi.org/10.3390/ijerph18073333

[7] Biasco-Duatis, M. y Coenders, G. (2020). Análisis de sentimiento de la agenda de los partidos políticos españoles en Twitter durante la Moción de Censura de 2018. Un enfoque de datos composicionales. Revista Mediterránea de Comunicación, 11 (2), 185-198.

http://dx.doi.org/10.14198/MEDCOM2020.11.2.22

[8] Blaszka, M.; Burch, L. M.; Frederick, E. L.; Clavio, G. \& Walsh, P. (2016). \#WorldSeries: An Empirical Examination of a Twitter Hashtag During a Major Sporting Event. International Journal of Sport Communication, 5(4), 435-453. http://dx.doi.org/10.1123/ijsc.5.4.435

[9] Bouguessa, M. \& Romdhane, L. BEN. (2015). Identifying authorities in online communities. ACM Transactions on Intelligent Systems and Technology, 6(3), 1-23. http://dx.doi.org/10.1 145/2700481

[10] Cha, M.; Haddadi, H.; Benevenuto, F. \& Gummadi, K. P. (2010). Measuring User Influence in Twitter: The Million Follower Fallacy. In 4th International AAAI Conference on Weblogs and Social Media (ICWSM).

[1 1] Chan-Olmsted, S. \& Xiao, M. (2019). Smart Sports Fans: Factors Influencing Sport Consumption on Smartphones. Sport Marketing Quarterly, 28(4), 181-194. http://dx.doi.org/10.32731/smq.284.122019.01 
[12] Clavio, G.; Walsh, P. \& Vooris, R. (2013). The utilization of Twitter by drivers in a major racing series. International Journal of Motorsport Management, 2(1), 2.

[13] De Nooy, W.; Mrvar, A. \& Bategelj, V. (2005). Exploratory Social Network Analysis with Pajek. Cambridge: Cambridge University Press. http://dx.doi.org/10.1017/cbo978051 1806452

[14] Delia, E. B. \& Armstrong, C. G. (2015). \#Sponsoring the \#FrenchOpen: An examination of social media buzz and sentiment. Journal of Sport Management, 29(2), 184-199.

http://dx.doi.org/10.1123/JSM.2013-0257

[15] Denia, E. (2021). Twitter como objeto de investigación en comunicación de la ciencia. Revista Mediterránea de Comunicación, 12(1), 289-301. http://dx.doi.org/10.14198/MEDCOM000006

[16] Dubois, E. \& Gaffney, D. (2014). The Multiple Facets of Influence: Identifying Political Influentials and Opinion Leaders on Twitter. American Behavioral Scientist, 58(10), 1260-1277.

http://dx.doi.org/10.1177/0002764214527088

[17] Gayo-Avello, D. (2013). Nepotistic relationships in twitter and their impact on rank prestige algorithms. Information Processing \& Management, 49(6), 1250-1280.

http://dx.doi.org/10.1016/j.ipm.2013.06.003

[18] González, L. M.; Devís-Devís, J.; Pellicer-Chenoll, M.; Pans, M.; Pardo-lbañez, A.; García-Massó, X.; Peset, F., Garzón-Farinós, F. \& Pérez-Samaniego, V. (2021). The impact of COVID-19 on sport in Twitter: A quantitative and qualitative content analysis. International Journal of Environmental Research and Public Health, 18(9). http://dx.doi.org/10.3390/ijerph18094554

[19] González-Bailón, S.; Borge-Holthofer, J. \& Moreno, Y. (2013). Broadcasters and Hidden Influentials in Online Protest Diffusion. American Behavioral Scientist, 57(7), 943-965.

http://dx.doi.org/10.1177/0002764213479371

[20] Greenhalgh, G. P. \& Greenwell, T. C. (2013). Professional niche sports sponsorship: an investigation of sponsorship selection criteria. International Journal of Sports Marketing and Sponsorship, 14(2), 2-19. http://dx.doi.org/10.1108/ijsms-14-02-2013-b002

[21] Greenwell, T. C.; Greenhalgh, G. \& Stover, N. (2013). Understanding spectator expectations: An analysis of niche sports. International Journal of Sport Management and Marketing, 13(3-4), 144-157. http://dx.doi.org/10.1504/IJSMM.2013.059720

[22] Gross, J. \& Von Wangenheim, F. (2018). The Big Four of Influencer Marketing. A Typology of Influencers. Marketing Review St. Gallen, 2, 30-38.

[23] Hambrick, M. E. (2016). Six Degrees of Information: Using Social Network Analysis to Explore the Spread of Information Within Sport Social Networks. International Journal of Sport Communication, 5(1), 16-34. http://dx.doi.org/10.1123/ijsc.5.1.16

[24] Hambrick, M. E. \& Sanderson, J. (2013). Gaining Primacy in the Digital Network: Using Social Network Analysis to Examine Sports Journalists' Coverage of the Penn State Football Scandal via Twitter. Journal of Sports Media, 8(1), 1-18. http://dx.doi.org/10.1353/jsm.2013.0003

[25] Hambrick, M. E.; Simmons, J. M.; Greenhalgh, G. P. \& Greenwell, T. C. (2010). Understanding Professional Athletes' Use of Twitter: A Content Analysis of Athlete Tweets. International Journal of Sport Communication, 3(4), 454-471. http://dx.doi.org/10.1123/ijsc.3.4.454

[26] Huang, Y.; Shen, C. \& Li, T. (2018). Event summarization for sports games using Twitter streams. World Wide Web, 21 (3), 609-627. http://dx.doi.org/10.1007/s1 1280-017-0477-6

[27] Hutchins, B. (2011). The acceleration of media sport culture: Twitter, telepresence and online messaging. Information Communication and Society, 14 (2), 237-257.

http://dx.doi.org/10.1080/1369118X.2010.508534

[28] Jensen, R. W.; Limbu, Y. B. \& Spong, Y. (2015). Visual Analytics of Twitter Conversations about Corporate Sponsors of FC Barcelona and Juventus at the 2015 UEFA Final. International Journal of Sports Marketing \& Sponsorship, 16(4), 3-9.

[29] Kang, S. J.; Rice, J. A.; Hambrick, M. E. \& Choi, C. (2019). CrossFit across Three Platforms: Using Social Media to Navigate Niche Sport Challenges. Physical Culture and Sport. Studies and Research, 81, 36-46. http://dx.doi.org/10.2478/pcssr-2019-0004 
[30] Kassing, J. W. \& Sanderson, J. (2010). Fan-Athlete Interaction and Twitter Tweeting Through the Giro: A Case Study. International Journal of Sport Communication, 3(1), 113-128.

http://dx.doi.org/10.1123/ijsc.3.1.113

[31] Katz, E. (1957). The Two-Step Flow of Communication: An Up-To-Date Report on an Hypothesis. Public Opinion Quarterly, 21 (1), 61-78. http://dx.doi.org/10.1086/266687

[32] Kwak, H.; Lee, C.; Park, H. \& Moon, S. (2010). What is Twitter, a social network or a news media? In Proceedings of the 19th International Conference on World Wide Web (pp. 591-600).

http://dx.doi.org/10.1145/1772690.1772751

[33] Lamirán-Palomares, J. M.; Baviera, T. \& Baviera-Puig, A. (2020). Sports influencers on Twitter. Analysis and comparative study of Track Cycling World Cups 2016 and 2018. Social Sciences, 9(10), 1-23. http://dx.doi.org/10.3390/socsci9100169

[34] Lara-Navarra, P.; López-Burrull, A.; Sánchez-Navarro, J. y Yànez, P. (2018). Medición de la influencia de usuarios en redes sociales: propuesta SocialEngagement. El Profesional de La Información, 27(4), 899-908. http://dx.doi.org/10.3145/epi.2018.jul.18

[35] Lee, S. \& Walsh, P. (2011). SWOT and AHP hybrid model for sport marketing outsourcing using a case of intercollegiate sport. Sport Management Review, 14(4), 361-369.

http://dx.doi.org/10.1016/j.smr.2010.12.003

[36] Marin-Garcia, J. A.; Aragonés-Beltrán, P. y García Melón, M. (2014). Consistencia intra e inter [1] evaluador de la comparación pareada en la evaluación de la competencia de innovación de estudiantes universitarios. WPOM-Working Papers on Operations Management, 5(2), 24.

https://doi.org/10.4995/wpom.v5i2.3220

[37] Mastromartino, B.; Qian, T. Y.; Wang, J. J. \& Zhang, J. J. (2020). Developing a fanbase in niche sport markets: An examination of NHL fandom and social sustainability in the sunbelt. Sustainability, 12 (3). http://dx.doi.org/10.3390/su12031115

[38] McCombs, M. \& Shaw, D. (1972). The Agenda-Setting Function of Mass Media. The Public Opinion Quarterly, 36(2), 176-187.

[39] Meenaghan, T.; Mcloughin, D. \& McCormack, A. (2013). New Challenges in Sponsorship Evaluation Actors, New Media, and the Context of Praxis. Psychology \& Marketing, 30 (5), 444-460. http://dx.doi.org/10.1002/mar.20618

[40] Méndez-Guzmán, E.; Zhang, Z. \& Ahmed, W. (2021). Towards understanding a football club's social media network: an exploratory case study of Manchester United. Information Discovery and Delivery, 49(1), 71-83. http://dx.doi.org/10.1108/IDD-08-2020-0106

[41] Miloch, K. S. \& Lambrecht, K. W. (2006). Consumer awareness of sponsorship at grassroots sport events. Sport Marketing Quarterly, 15(3), 147-154.

[42] Naraine, M. L. (2019). Follower Segments Within and Across the Social Media Networks of Major Professional Sport Organizations. Sport Marketing Quarterly, 28(4), 222-233.

http://dx.doi.org/10.32731/smq.284.122019.04

[43] Naraine, M. L.; Schenk, J. \& Parent, M. M. (2016). Coordination in international and domestic sports events: Examining stakeholder network governance. Journal of Sport Management, 30 (5), 521-537. http://dx.doi.org/10.1123/jsm.2015-0273

[44] Nisar, T. M.; Prabhakar, G. \& Patil, P. P. (2018). Sports clubs' use of social media to increase spectator interest. International Journal of Information Management, 43, 188-195.

http://dx.doi.org/10.1016/j.jijnfomgt.2018.08.003

[45] Page, L. \& Brin, S. (1998). The anatomy of a large-scale hypertextual Web search engine. Computer Networks, 30(1-7), 107-1 17. http://dx.doi.org/10.1016/s0169-7552(98)00110-x

[46] Pegoraro, A. (2016). Look Who's Talking-Athletes on Twitter: A Case Study. International Journal of Sport Communication, 3(4), 501-514. http://dx.doi.org/10.1123/ijsc.3.4.501

[47] Riquelme, F. \& González-Cantergiani, P. (2015). Measuring user influence on Twitter: A survey. Information Processing and Management, 52(5), 949-975. http://dx.doi.org/10.1016/j.ipm.2016.04.003 
[48] Rubio García, R. (2014). Twitter y la teoría de la AgendaSetting: mensajes de la opinión pública digital. Estudios sobre el Mensaje Periodístico, 20(1), 249-264.

http://dx.doi.org/10.5209/rev_ESMP.2014.v20.n1.45230

[49] Saaty, T. (1980). The analytic hierarchy process: Planning, priority setting, resource allocation. New York: McGraw-Hill.

[50] Saaty, T. L. (2008). Decision making with the analytic hierarchy process. International Journal of Services Sciences, 1 (1), 83-98. http://dx.doi.org/10.1504/IJSSCI.2008.017590

[51] Sanderson, J. \& Hambrick, M. E. (2016). Covering the Scandal in 140 Characters: A Case Study of Twitter's Role in Coverage of the Penn State Saga. International Journal of Sport Communication, 5(3), 384-402. http://dx.doi.org/10.1123/ijsc.5.3.384

[52] Santomier, J. (2008). New media, branding and global sports sponsorship. International Journal of Sports Marketing and Sponsorship, 10(1), 15-28. http://dx.doi.org/10.1 108/ijsms-10-01-2008-b005

[53] Scelles, N.; Helleu, B.; Durand, C.; Bonnal, L. \& Morrow, S. (2017). Explaining the number of social media fans for North American and European professional sports clubs with determinants of their financial value. International Journal of Financial Studies, 5(4), 1-20. http://dx.doi.org/10.3390/ijf55040025

[54] Scott, J. (2017). Social Network Analysis. Londres: SAGE.

[55] Sinuany-Stern, Z. (1988). Ranking of sports teams via the AHP. Journal of the Operational Research Society, 39(7), 661-667. http://dx.doi.org/10.1057/jors.1988.112

[56] Smith, L. R.; Pegoraro, A. \& Cruikshank, S. A. (2019). Tweet, Retweet, Favorite: The Impact of Twitter Use on Enjoyment and Sports Viewing. Journal of Broadcasting and Electronic Media, 63(1), 94-1 10. http://dx.doi.org/10.1080/08838151.2019.1568805

[57] Su, Y.; Baker, B. J.; Doyle, J. P. \& Kunkel, T. (2020). The Rise of an Athlete Brand: Factors Influencing the Social Media Following of Athletes. Sport Marketing Quarterly, 29, 33-46.

[58] Tafesse, W. \& Wood, B. P. (2021). Followers' engagement with Instagram influencers: The role of influencers' content and engagement strategy. Journal of Retailing and Consumer Services, 58, 102303. http://dx.doi.org/10.1016/j.jretconser.2020.102303

[59] Thompson, A. J.; Martin, A. J.; Gee, S. \& Geurin, A. N. (2018). Building brand and fan relationships through social media. Sport, Business and Management: An International Journal, 8(3), 235-256. http://dx.doi.org/10.1 108/SBM-04-2017-0024

[60] Trivedi, J.; Soni, S. \& Kishore, A. (2021). Exploring the Role of Social Media Communications in the Success of Professional Sports Leagues: An Emerging Market Perspective. Journal of Promotion Management, 27(2), 306-331. http://dx.doi.org/10.1080/10496491.2020.1829774

[61] Vale, L. \& Fernandes, T. (2018). Social media and sports: driving fan engagement with football clubs on Facebook. Journal of Strategic Marketing, 26(1), 37-55.

http://dx.doi.org/10.1080/0965254X.2017.1359655

[62] Veglis, A. \& Maniou, T. A. (2018). The mediated data model of communication flow: Big data and data journalism. Kome, 6(2), 32-43. http://dx.doi.org/10.17646/KOME.2018.23

[63] Wang, X. (2015). Using attitude functions, self-efficacy, and norms to predict attitudes and intentions to use mobile devices to access social media during sporting event attendance. Mobile Media \& Communication, 3(1), 75-90. http://dx.doi.org/10.1177/2050157914548932

[64] Wang, Y. (2021). Building relationships with fans: How sports organizations used Twitter as a communication tool. Sport in Society, 24 (7), 1055-1069. http://dx.doi.org/10.1080/17430437.2020.1725475

[65] Wäsche, H. (2015). Interorganizational cooperation in sport tourism: A social network analysis. Sport Management Review, 18(4), 542-554. http://dx.doi.org/10.1016/j.smr.2015.01.003

[66] Wäsche, H.; Dickson, G.; Woll, A. \& Brandes, U. (2017). Social network analysis in sport research: an emerging paradigm. European Journal for Sport and Society, 14 (2), 138-165.

http://dx.doi.org/10.1080/16138171.2017.1318198 
[67] Wasserman, S. \& Faust, K. (1994). Social Network Analysis: methods and applications. Cambridge: Cambridge University Press. http://dx.doi.org/10.1017/CBO9780511815478

[68] Yan, G.; Watanabe, N. M.; Shapiro, S. L.; Naraine, M. L. \& Hull, K. (2019). Unfolding the Twitter scene of the 2017 UEFA Champions League Final: social media networks and power dynamics. European Sport Management Quarterly, 19(4), 419-436. http://dx.doi.org/10.1080/16184742.2018.1517272

[69] Zhang, Y.; Moe, W. W. \& Schweidel, D. A. (2017). Modelling the role of message content and influencers in social media rebroadcasting. International Journal of Research in Marketing, 34 (1), 100-1 19. http://dx.doi.org/10.1016/j.jiresmar.2016.07.003 